\title{
Nanowire-Based Biosensors: From Growth to Applications
}

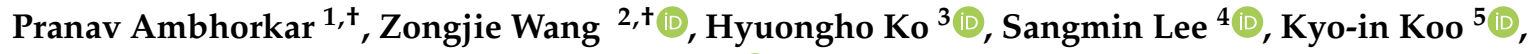 \\ Keekyoung Kim ${ }^{1, *}$ and Dong-il (Dan) Cho ${ }^{6, *(1)}$ \\ 1 School of Engineering, University of British Columbia, Kelowna, BC V1V 1V7, Canada; \\ pambhorkar@yahoo.com \\ 2 Department of Electrical and Computer Engineering, Institute of Biomaterials and Biomedical Engineering, \\ University of Toronto, Toronto, ON M5S 3M2, Canada; zongjie.wang@utoronto.ca \\ 3 Department of Electronics, Chungnam National University, Daejeon 34134, Korea; hhko@cnu.ac.kr \\ 4 Department of Biomedical Engineering, Kyung Hee University, Yongin 17104, Korea; sangmlee@khu.ac.kr \\ 5 Department of Biomedical Engineering, University of Ulsan, Ulsan 44610, Korea; kikoo@ulsan.ac.kr \\ 6 ASRI/ISRC, Department of Electrical and Computer Engineering, Seoul National University, Seoul 08826, \\ Korea \\ * Correspondence: keekyoung.kim@ubc.ca (K.K.); dicho@snu.ac.kr (D.-i.C.); Tel.: +1-250-807-8040 (K.K.); \\ $+82-2-880-6488$ (D.-i.C.) \\ + These authors contribute equally to this work.
}

Received: 30 November 2018; Accepted: 17 December 2018; Published: 19 December 2018

\begin{abstract}
Over the past decade, synthesized nanomaterials, such as carbon nanotube, nanoparticle, quantum dot, and nanowire, have already made breakthroughs in various fields, including biomedical sensors. Enormous surface area-to-volume ratio of the nanomaterials increases sensitivity dramatically compared with macro-sized material. Herein we present a comprehensive review about the working principle and fabrication process of nanowire sensor. Moreover, its applications for the detection of biomarker, virus, and DNA, as well as for drug discovery, are reviewed. Recent advances including self-powering, reusability, sensitivity in high ionic strength solvent, and long-term stability are surveyed and highlighted as well. Nanowire is expected to lead significant improvement of biomedical sensor in the near future.
\end{abstract}

Keywords: nanowire; sensor; biological applications; medical applications; nanomaterial

\section{Introduction}

Biomedical sensors with high sensitivity could make it possible to detect diseases in their early state, drastically increasing the chance of potentially life-saving detection and intervention. For example, when breast cancer is detected at an early stage (local disease) and treated with existing therapies, the five year survival rate is greater than $90 \%$, but drops to around $20 \%$ upon developing into late stages (distant disease) [1]. Highly sensitive biosensors for the early detection of cancer are yet demanded [2,3]. Though much research has been carried out in an attempt to increase the sensitivity of biomedical sensors, recent developments in nanotechnology will provide the most promising solutions in the area of biomedical sensing $[4,5]$. Nanotechnology includes broad science and engineering research areas to study materials and structures less than approximately $100 \mathrm{~nm}$ [6]. In case of the nanometer scale, physical and chemical properties of materials are highly dependent on surface-to-volume ratios and quantum size effects, resulting in completely different properties than those at the macroscale [7].

Since the surface area-to-volume ratio is enormous at the nanoscale, it affects most of the regions on the sensing structure, making a nanostructure ultrasensitive to changes on its surface. The electron 
movement of the nanostructure is confined by quantization effects, resulting in quantum size effects, in which the discrete energy levels of the device depend on the size of the structure. In addition, both the excited energy of semiconductors at the lowest state and the strength of volume-normalized oscillator are increased by decreasing the scale [8], allowing the nanostructures to have a high energy conversion efficiency and relatively low thermal noise [9]. The size of biomolecules ( 10 to 100 nm), which is in the same range of synthetic nanostructures, also benefits the development of biomedical sensors using nanotechnology.

The primary task of biomedical sensors is to detect and characterize chemical and biological species, ranging from applications in disease diagnosis to drug discovery. Using nanomaterials (e.g., nanowires, carbon nanotubes, and nanoparticles) with distinct optical, magnetic, and electrical properties, those primary biomedical tasks can be achieved readily [10]. For examples, semiconductor crystalline nanoparticles were used to detect the labeled disease markers and other biological species [11,12], and colloidal gold was used in optical imaging and magnetic resonance [13,14]. In addition, semiconductor nanowires made it possible to detect various species electrically and without labels [15]. These nanowires were fabricated from semiconductor materials [16] and their surface can be readily modified to become sensitive to chemical and biological species $[17,18]$. Carbon nanotubes, which can also be employed in biomedical sensors, however, are synthesized by mixing semiconductor materials and metals, requiring further purification $[19,20]$. In addition, the binding protocols of a variety of analytes to nanotubes have not been well established [16,21]. Therefore, nanostructures fabricated by nanowires are the most suitable option for biomedical sensors that have high sensitivity, uniformity, reproducibility, and scalability with relatively simple fabrication process [22,23].

This review includes working principles of nanowire-based biomedical sensors and a variety of applications in biological and medical fields, updating our previous reports [24,25], which do not overlap the contents of this paper. We also discuss the advancement of long-term stability, sensitivity in solvents with high ionic strength, reusability, and self-powering, as those advancements significantly impact on overcoming the current limitations of nanowire-based biomedical sensors.

\section{Working Principle and Fabrication Process}

\subsection{Fundamentals of Nanowire Field-Effect Transistors}

Nanowire field-effect transistors (FETs) are a type of nanowire sensor that have originated from the standard planar FETs which consist of a gate, source, drain, and the body (Figure 1A). With a metallic material, the source and drain on the body are fabricated at the micro- or nanoscale. The gate, a critically thin isolation layer (e.g., $\mathrm{SiO}_{2}$ ), is fabricated between the source and drain, and generates electric potential variations to adjust the conductivity between the source and drain [26]. These variations in electric potential are usually in response to the application of an external voltage. Chemically or biologically charged species can also alter the potential and then conductivity by binding the charged species to the gate. This type of an electrical detection mechanism through an accumulation of charged species was proposed several decades ago [27]. However, it requires a lot of samples for detection due to the low sensitivity, preventing the use of the planar gate FET sensor in many applications.

In the nanowire FETs, doped channels and gates are replaced with nanowires and receptors, respectively (Figure 1A). Even though the structures of the FETs are different, the working principle of nanowire FETs remains the same as standard FETs in which the conductivity of nanowires (i.e., doped channels) is altered by external changes caused by charged species. Among various semiconductor nanowires that can be fabricated by silicon or other materials [28-30], silicon and silica nanowires are most widely used due to their high compatibility with the standard CMOS (complementary metal-oxide-semiconductor) technology. The natural growth of the oxide layer as the isolation layer on the silicon surface, and the easy modification of the silicon and silica surface, are other benefits of silicon and silica nanowires. Although the biomolecules have charges, the accumulation 
of biomolecules on the isolation layer does not alter the conductivity of nanowires since the original silicon and silica surface is not sensitive to biomolecules [14]. Therefore, it is necessary to make the surface functionalized and bound by receptors for sensing the specific charged species (e.g., DNA, RNA, viruses, etc.). By functionalizing the nanowire FETs, chemical connections between the surface of isolation layers coated on nanowires and biomolecules can be made (Figure 1B). Then, the receptors, which bind the collected species, induce an electric field onto the nanowires and alter the conductivity of nanowires. As we consider species as an input signal, the receptors play a similar role to the gate since they convert the input signal to changes in the conductivity of devices. Figure $1 \mathrm{~B}$ shows a typical binding process using 3-aminopropoyltriethoxysilane (APTES), which is a type of receptor for DNA, peptide nucleic acid (PNA), and antibodies [16]. APTES converts silicon-oxygen bonds to a silane chemistry layer (Si-O-Si-X), where $\mathrm{X}$ can be modified further or linked with specific receptors.
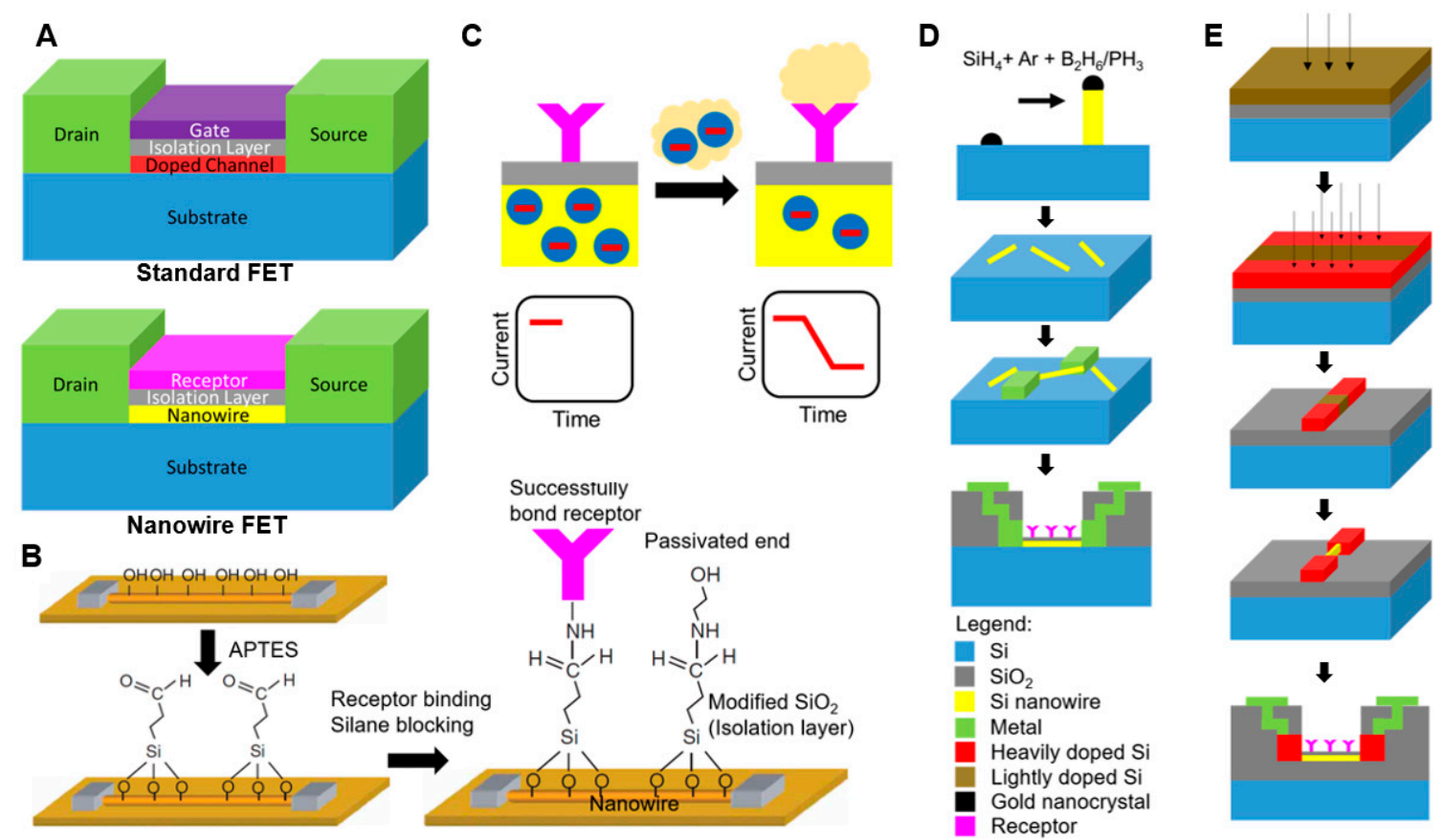

Figure 1. Conceptual overview of field effect transistors (FET) (adopted with permission from [24]). (A) Schematics illustrating the differences between standard and nanowire field-effect transistors. (B) An overview of the functionalization process of the nanowire (based on 3-aminopropoyltriethoxysilane (APTES)). The APTES converts the silicon-oxygen bonds into a silane layer, after which, it becomes possible to bind this layer with several receptors (adopted with permission from [31]). (C) Illustrates the operating principles of nanowire sensors. The charged molecules captured by the receptors induce variations in the conductivity of nanowire (there is either an increase or a decrease in the current that passes through it). The nanowire sensors fabricated using (D) the bottom-up approach and (E) the top-down approach.

Figure $1 \mathrm{C}$ shows the working principle of the nanowire sensor. Upon the binding of the negatively charged species in an aqueous solution to the receptor, positive charges are induced on the $\mathrm{Si}$ nanowire FET surface. The generation of positive charges can either be considered as the disappearance of electrons (negatively charged carriers) or the appearance of holes (positively charged carriers), therefore changing the conductivity (or current) between the source and the drain. In the n-type Si nanowire, the conductivity will decrease as the charge carriers in this case are electrons. On the contrary, in p-type Si nanowires, the current will increase as the charge carriers in p-type nanowires are holes. A semiconductor parameter analyzer is used for the real-time monitoring of conductivity from the Si nanowire FETs [32,33]. Unlike the typical FETs on electronic circuit boards, the nanowire FET is usually in the ON state (i.e., DC currents always pass through). Also, since multiple 
nanowires are usually more sensitive to the accumulation of species and experience lower statistical noise as a result of averaging, an array of nanowires is commonly used in a single sensing device [34].

Surface charge variation of the isolation layer is another factor of changes in the conductivity of nanowires. The $\mathrm{pH}$ of solvents affects the surface charge of nanowires, resulting in the alteration of the conductivity of nanowires [14]. At low $\mathrm{pH}$, the surface terminating in $-\mathrm{NH}_{2}$ group, as shown in Figure 1B, consumes positively charged holes from the nanowire surface and becomes $-\mathrm{NH}_{3}{ }^{+}$. At high $\mathrm{pH},-\mathrm{SiOH}$ consumes electrons from the nanowire surface and becomes - $\mathrm{SiO}-$. The conductivity changes of nanowires due to $\mathrm{pH}$ is a combined effect of these two mechanisms [14]. The $\mathrm{pH}$ is an important factor to maintain the accuracy of nanowire sensors since measurement data from the same solutions with different $\mathrm{pH}$ will be inconsistent.

Counterion condensation effect also contributes to the conductivity of nanowires. For instance, if the bound molecules are negatively charged in the solvent, they will be surrounded by positively charged counterions due to electrostatic interactions. Positive charges from counterions on a certain length are attracted to negative charges from the target biomolecules. As a result, charges from the target biomolecules are eliminated [35]. This length is called Debye length $\left(\lambda_{d}\right)$. The Debye length is the measure of a charge carrier's net electrostatic effect in a solution, which means how far those electrostatic effects are maintained. Therefore, the Debye length is critical for sensors to be able to differentiate the signal from target molecules that are in an electrostatic system. Over the Debye length, the negatively charged molecules become electrically neutral as the effect of negative charges is offset by positive charges coming from the electrostatic interaction of analytes, contributing to no changes in the conductivity of the nanowire. Therefore, only the target molecules within the Debye length contribute to the conductivity change. In addition, the detectability of negatively charged molecules decreases as the Debye length is shortened [35]. Long-enough Debye lengths can fully detect the charged molecules with high sensitivity. In the design of nanowire sensors, an optimal Debye length is a major parameter to be carefully considered, and a long Debye length ensures the counterions effect small [36]. The Debye length for the nanowire sensors can be approximately calculated as $\lambda_{D} \approx 0.304 I^{-0.5}$, where $I$ is the ionic strength of the solvent solution [37,38]. As in the equation, the Debye length gets increased as the ionic strength gets decreased. Thus, the sensitivity of nanowire sensor with a less conductive solvent is better than with the more conductive solvent. Significant increments in the Debye length was obtained by diluting the phosphate buffered saline (PBS) with the deionized water [39].

\subsection{Fabrication Process}

There are bottom-up and top-down methods that are utilized for the fabrication of nanowire sensors. As shown in Figure 1D, the bottom-up methods have been used to grow high-quality nanowires commonly on Si wafers [40]. Although most nanowires are cylindrical in shape, existing bottom-up techniques are capable of varying their cross-sectional shape, producing round, square, and triangular versions [41]. The fabrication process starts with growing Si nanowires using the chemical vapor deposition (CVD) method [31]. Si nanowires can be grown catalytically in the CVD reaction via the vapor-liquid-solid (VLS) mechanism [42]. Subsequently, the Si nanowires suspended in ethanol solution are deposited onto a silicon substrate. A photoresist is then spin-coated onto the substrate with deposited Si nanowires, and then the metal electrodes are patterned by the lift-off method process. The bottom-up fabrication ends with passivation and surface modification with receptor binding [31]. The isolation layer on the nanowire surface is easily achieved by exposing it to air or an oxygen environment. The bottom-up approach has a drawback of the randomly oriented nanowires, leading to the poor uniformity and low yield rate of nanowire sensors. In order to improve the orientation, additional alignment steps during fabrication are required, such as Langmuir-Blodgett [43], blown-bubble [44], microfluidic flow [45], contact printing [46], and electric-field [47,48]. Nevertheless, the standard CMOS fabrication process is not compatible with those alignment methods, making the mass production of the aligned nanowire sensors difficult. 
Unlike the bottom-up methods, the top-down methods, based on the microfabrication process on a silicon-on-insulator (SOI) wafer or a single-crystalline silicon (SCS) wafer, can fabricate aligned nanowires that are compatible with the standard CMOS technology. As shown Figure 1E, the fabrication process starts from doping low-density boron or phosphorous on the top Si layer of a SOI wafer. Subsequently, heavy density doping on the patterned area is conducted to define the source and drain leads, followed by forming micrometer-sized source and drain electrodes using reactive ion etching (RIE). Then, electron-beam (E-beam) lithography is used to fabricate nanometer-sized Si nanowires and the metal contact leads are formed by a thermal evaporation. Finally, the fabrication process ends with passivation and surface modification, same as the bottom-up method $[49,50]$. While the top-down methods are highly compatible with the CMOS processes with well-oriented nanowires, the diameter of nanowires is bigger than nanowires produced via the bottom-up method. Despite differences in nanowire orientation and materials for drain and source, these devices share the same architecture (e.g., drain/nanowire/source).

Another silicon nanowire fabrication process using a top-down process based on bulk SCS wafer is shown in Figure 2. Generally, the fabrication is performed with combined processes of typical semiconductor manufacturing process, which uses photolithography, silicon dry etching, anisotropic wet etching, and thermal oxidation [51-53]. In these top-down fabrication methods, the width of the silicon nanowires is controlled by the thermal wet oxidation time. Its result is organized silicon nanowires. The schematics of the fabrication processes of (100)- and (111)-oriented SCS wafer are illustrated in Figure 2A,B respectively. For the (100)-silicon fabrication process, a 1000- $\AA$-thick silicon dioxide is grown on the boron-doped silicon substrate using a thermal oxidation process. After photolithographic definition of the space and line, the silicon dioxide at the top layer is etched by the dielectric etching process. Then, photoresists are removed, and cleaning processes are performed. Then, the silicon deep RIE etching process is performed to define the rectangular-structured columns, where the silicon nanowires are located. Subsequently, anisotropic silicon wet etching process, using tetramethylammonium hydroxide (TMAH) solution, is carried on until the $\{111\}$-plane of the silicon surface is exposed. As shown in the Figure 2A, the hourglass-shaped silicon structures are fabricated, exposing the etch-stop $\{111\}$-surfaces. The arrayed silicon nanowire structures are fabricated by a thermal oxidation process, in which the upper layers of the hourglass structures are the silicon nanowires, and are isolated by the thermal oxide between the upper and lower layer. The height of the nanowire is determined by the photolithographic pattern width, which is an inherent property of the SCS wafer. The top-down (111)-silicon nanowire fabrication also starts with the thermal oxide growth process. Then, photolithography and dielectric etching processes are performed to define the line and space patterns. The primary deep silicon RIE process is performed for defining the height of the silicon nanowire. For (111)-silicon nanowires, the height and the width of the structures are defined separately, which can result in various structures, such as wires and ribbons. Then, thermal oxidation process is performed for passivation of the sidewalls of the whole structures. The plasma-enhanced anisotropic dielectric dry etching process is performed to expose the bottom surface of the structure, and secondary deep silicon RIE process is performed to fabricate the sacrificial layer. Subsequently, an anisotropic silicon wet etching process by TMAH solution is followed to reveal the $\{111\}$-planes. Finally, the thermal oxidation process is performed to fabricate the arrayed rectangular nanowire structures, after the passivated silicon dioxide layers' removal.

One of critical components of the nanowire sensors is the fluid exchange system. The fluid exchange system delivers analytes or fluids to, or close to, the surface of the nanowire sensor. Polydimethylsiloxane (PDMS)-based channel devices are widely used for feeding analytes to nanowire sensors. In biosensing applications, PDMS is also advantageous due to its high biocompatibility $[54,55]$. However, the PDMS-based microfluidic fluid exchange system has a few limitations. Since fluid flow in microscale channels is characterized by laminar flow, particles inside the microfluidic channels are difficult to approach the surface of the nanowire sensors. In addition, there is the possibility of sensitivity reduction of the sensor as PDMS can absorb biomolecules [54]. In order to overcome these 
limitations of PDMS microfluidic channels, an acrylic chamber as a fluid exchange system has been developed [56].

A

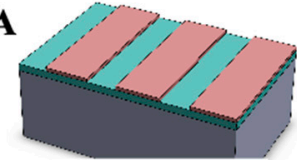

(1) Wet oxidation \& Photolithography

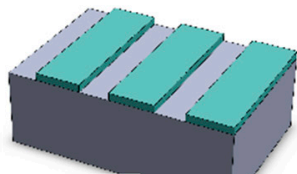

(3) PR strip

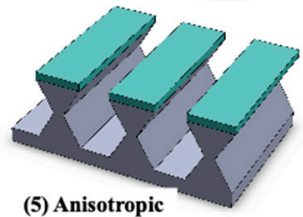
Wet etching

B

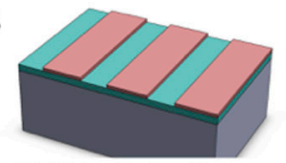

(1) Wet oxidation \& Photolithography

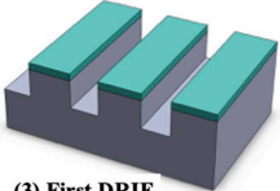

(3) First DRIE

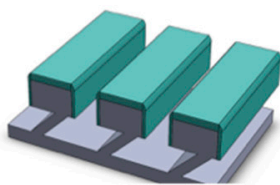

(5) Second DRIE \& Wet etching

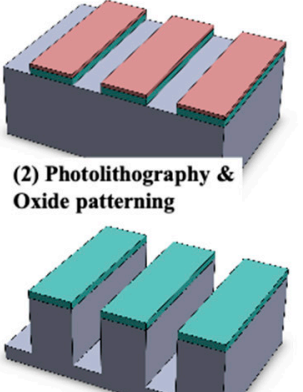

(4) DRIE

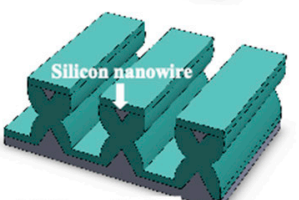

(6) Wet oxidation

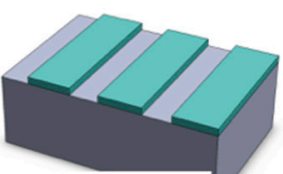

(2) Oxide patterning

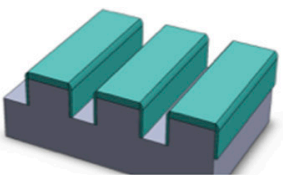

(4) Sidewall passivation \& Bottom etch

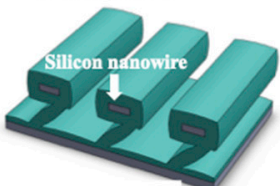

(6) Wet oxidation
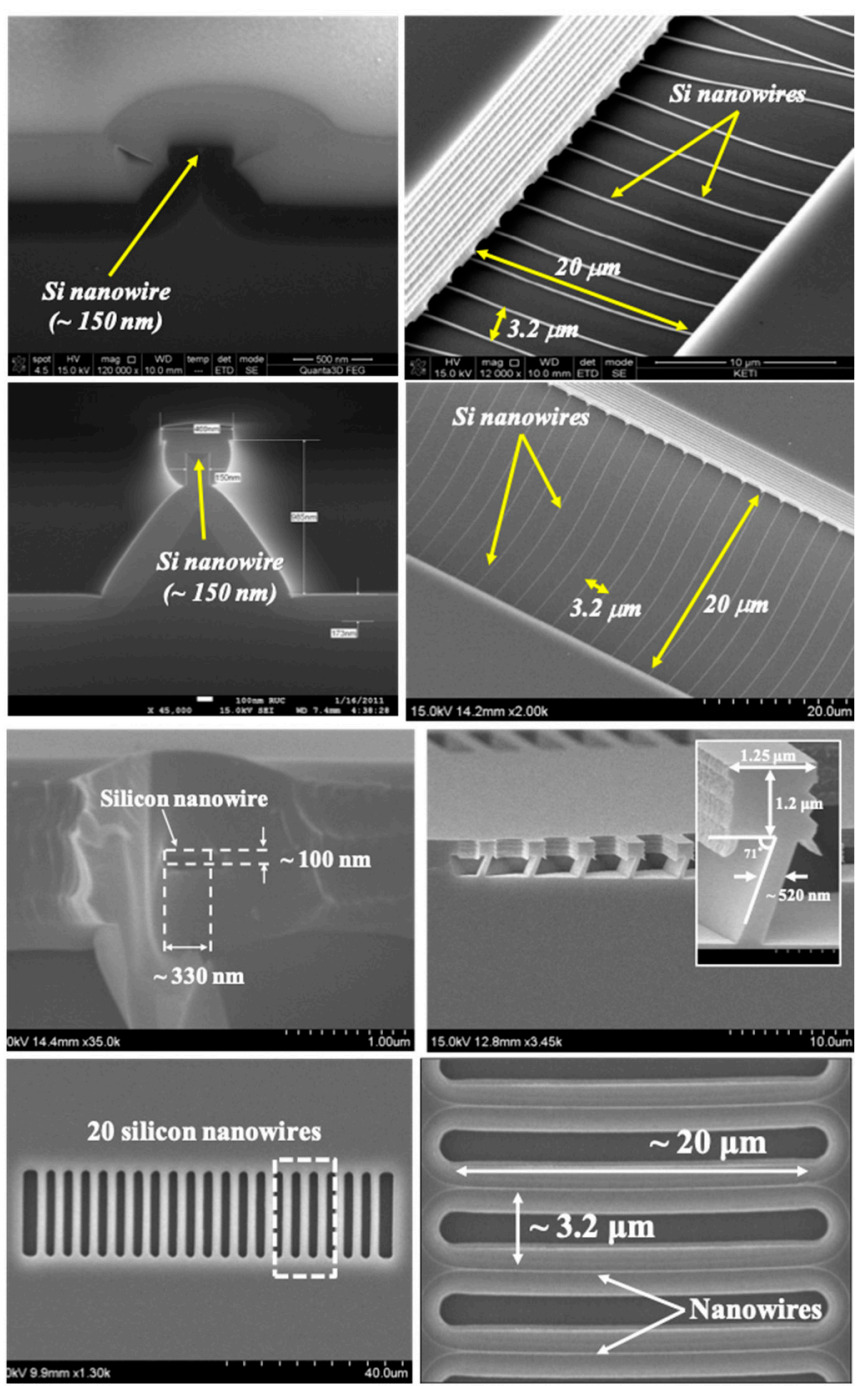

Figure 2. Top-down fabrication process and results using single-crystalline silicon (SCS) wafer. (A) (100)-silicon (adopted with permission from [51,52]). (B) (111)-silicon (adopted with permission from [53]).

\section{Detection of Various Biological Agents}

\subsection{Proteins}

Several new biomarkers have been discovered through research in proteomics and genomics that could potentially be used for diagnosing diseases [1]. In order to diagnose complicated diseases like cancer, that are characterized by considerable heterogeneity, single marker tests do not yield acceptable diagnoses [3]. It is important, therefore, to consider multiple biomarkers [6]. This is especially important for the treatment of cancer, where the detection of multiple biomarkers could determine the stage of the disease [6]. The first application of p-type silicon nanowire sensors was to detect proteins in a solution, electrically [16]. Since then, various nanowire and nanowire array-based platforms have been developed for simultaneously detecting multiple disease marker proteins $[28,33,57,58]$. 
Many contemporary studies have converged on developing platforms that can detect these disease markers real-time [59], as well as directly from whole blood [60]. It is also possible now to detect a wider variety of biomarkers like cardiac biomarkers [56]. Recent work has also demonstrated the application of nanostructured sensing platforms in detecting many proteins, label free, making it possible to diagnose pregnancy and diseases like diabetes, Parkinson's disease, atherothrombosis, and autoinflammatory diseases [61]. Furthermore, recently, nanowire-on-a-chip platforms have been developed for the comprehensive detection of biomolecules, wherein nanowires carry out preconcentration, separation, filtering, and detection, enabling rapid and practical clinical use [62].

Janissen et al. presented comprehensive work that characterizes the effects of surface functionalization and covalent immobilization for protein detection from pathogens. In the study, surface functionalization with APTES, ethanolamine, was compared to the surface passivation via poly(ethylene glycol) (PEG) (Figure 3A). It was found that, compared to APTES, applying ethanolamine significantly promoted the bioreceptor density and coating homogeneity (Figure 3B,C). In addition, applying PEG led to many benefits, including (1) higher ligand binding specificity due to the reduction in non-specific adhesion; (2) increased receptor/ligand binding based on spatial separation; (3) additional spatial mobility for immobilized antibody, which further improves the antigen binding; and (4) minimized Debye length for sensing. They further applied the optimized functionalization strategy to detect a Chagas disease protein biomarker, IBMP8-1. The limit of detection (LOD) and minimal concentration detection are $5.7 \mathrm{fM}$ and $32 \mathrm{fM}$, respectively, in serum (Figure 3D). The linear sensitivity region ranges from 90 to $500 \mathrm{fM}$. This article incorporates many recent strategies together and provides an improved methodology to fabricate robust, reliable, and sensitive protein biosensors using nanowires in a multiplexing format.

A

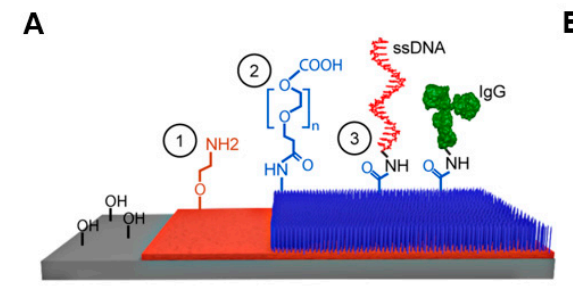

D

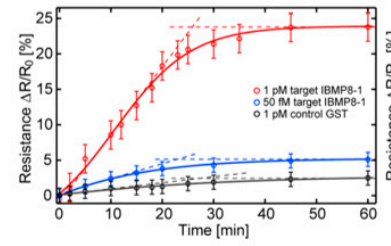

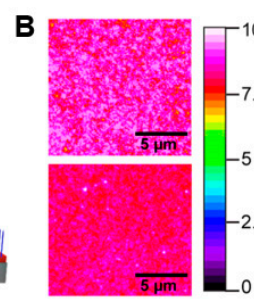

E

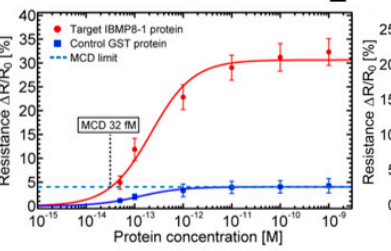

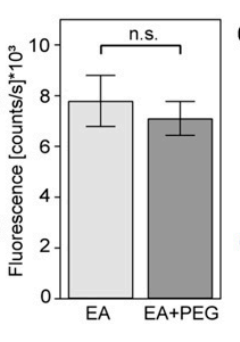

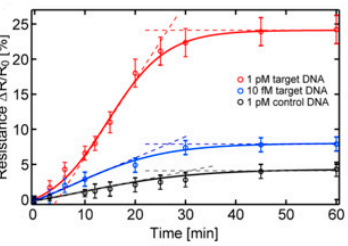

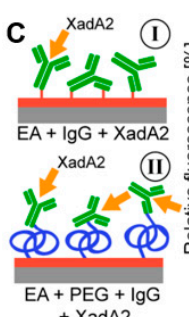

+ XadA2

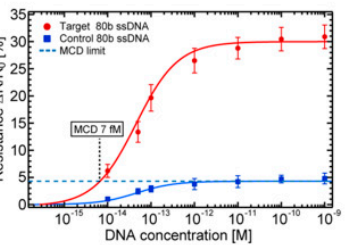

Figure 3. Generalized strategy for ultrasensitive detection of protein and DNA using nanowires (adopted with permission from [62]). (A) Schematic representing the functionalization process to allow high sensitivity. (1) Coupling ethanolamine to the surface; (2) attaching PEG cross-linker; (3) binding of biomolecules by peptide-binding. (B) False-colored image of fluorophore antibodies bound to the ethanolamine and PEGylated surfaces. No statistical difference was found on the amount of fluorescence. (C) PEGylated surface has higher relative fluorescence. The schematic illustrated the spacing introduced by PEG significantly improved the binding efficiency of antibodies. (D,E) Detection of protein antigen (D) and ssDNA (E) using the developed devices. The LOD is $6 \mathrm{fM}$ and $1 \mathrm{fM}$ for protein and ssDNA, respectively.

\subsection{DNA and RNA}

It possible to detect specific sequences of DNA and RNA with nanowire sensors [63]. The surfaces of silicon nanowires consist of single-stranded sequences of PNAs that are placed to act as receptors for DNA [64]. The capability of silicon nanowires to detect DNA at the 10 femtomolar level has been 
demonstrated [65]. This is significantly better for DNA detection as compared to the quartz-crystal microbalance [66], surface plasmon resonance (SPR) [67] and nanoparticle-enhanced SPR [68].

The strategy introduced by Janissen et al. can also be applied to further improve the specificity and sensitivity of nanowire sensors [62]. Preliminary data revealed that the LOD of ssDNA detection of around 1 femtomolar level is achievable [62] (Figure 3E). In addition to the detection of individual strands of DNA, nanowires can also be utilized to detect the bonding between protein and DNA $[38,69,70]$.

Similarly, nanowire devices can become RNA sensors by functionalizing PNA or DNA. For example, Lu et al. presented a way to fabricate a Si nanowire biosensor via anisotropic wet etching with self-limitation of $\mathrm{Si}<111>$ using tetramethylammonium hydroxide (TMAH) [71]. The self-limitation dramatically improved the uniformity of devices and lowered the manufacturing cost. This low-cost biosensor demonstrated a rapid detection of miR-21 and miR-205, two cancer-associated miRNAs, with the low limit of detection (LOD) down to 1 zeptomole. It also demonstrated great selectivity by clearly identifying the difference between target miRNA and a single-nucleotide mismatched sequence, as well as performing proper detection for spiked serum samples. In addition, nanowire biosensors have also been applied to detect virus gene in a label-free fashion. Huang et al. reported a strategy to amplify the detected signal via exonuclease III-assisted target recycling and achieved a LOD of 3.6 pM [72].

The capability of monitoring various cancer biomarkers in the DNA level, such as telomerase and carcinoembryonic antigen, opens a door for the use of nanowire-based DNA sensors for cancer diagnosis and treatment $[33,73]$. Recently, Yasui et al. unveiled massive number of cancer-related urinary microRNA candidates ( 1000 types) with the help of multiplexed nanowires, covering not only the urologic malignancies (i.e., bladder and prostate) but also for other cancers (lung, pancreas, and liver). This provides a foundation for long-term work aiming to setup urine-based checkups for cancer [74]. However, in addition to this study, to date, the level of multiplexing is still below the demand for clinical needs. Simultaneous detection of multiple types of analytes from the same specimen holds the key to providing valuable data for downstream analysis and diagnostics [75]. The demand for high-throughput multiplexing has become even more critical when combined with machine learning-based diagnostics as it requires a large amount of data for proper training and accurate detection [75].

\subsection{Viruses}

The effective detection of viruses is one of the most important tasks of nanowire sensors for keeping our societies healthy and safe, since most viruses cause serious human diseases and can be used as biological weapons [76,77]. In recent years, Si nanowire sensors have been used to detect many dangerous viruses, including Dengue [78], influenza A H3N2 [79], H1N1 [80], and HIV [81]. The nanowire sensor surface is functionalized with antibodies that specifically bind to the target viruses, affecting the conductivity of the nanowire. For instance, Shen et al. developed a Si nanowire-based biosensor that could detect as many as $29 \mathrm{flu}$ viruses/ $\mu \mathrm{L}$ from exhaled breath condensate (EBC) samples [79]. Recently, Ibarlucea et al. introduced Si nanowires to detect Ebola VP40 matrix protein [82]. The limit of detection (LOD) was seen to be around $6.25 \mathrm{nM}$ after $30 \mathrm{~min}$ incubation, outperforming the ELISA technique by six orders. With advantages including rapidness, accuracy, and portability, nanowire biosensors will play an increasingly important role in the point-of-care diagnostics of epidemic diseases.

\section{Recent Advances in Nanowire Biosensors}

This section provides a brief introduction to the important technologies that have emerged in recent years to solve the intrinsic problems of traditional nanowire-based biosensors, including in vivo sensing, integration with low-cost portable devices, and new strategies to process measured signals. With the help of these technologies, nanowire-based biosensors have become more practical and suitable for various biomedical applications. 


\subsection{In Vivo Sensing}

The traditional applications of nanowires are mostly in vitro. However, recently, more work has been conducted in investigating sensors that can provide a continuous measurement of biosignals in vivo. Pilot studies by the Lieber group have demonstrated the possibility of injecting the nanowire sensors into human body for long-term recording of bioelectric signals, such as neural activities in the brain $[83,84]$. The in vivo environment presents a lot of challenges to the properties of nanowires. On the one hand, the in vivo microenvironment contains many ions that can dissolve the passivation layer (silicon oxidation) of silicon nanowires which naturally exist in air $[85,86]$. Early studies have reported the limited stability of nanowires upon being used with cells [87,88]. Zhou et al. recently introduced a coating method to enhance the long-term stability of nanowires [89]. Upon studying the protection of the $10 \mathrm{~nm}$-thick $\mathrm{Al}_{2} \mathrm{O}_{3}$ shell, it was observed that the diameter of the nanowire remained almost the same for at least 100 days in $1 \times \mathrm{PBS}$ at $37^{\circ} \mathrm{C}$, respectively, while the nanowire without the shell disappeared (Figure 4A). This coating strategy worked not only for Si nanowire, but also for Si-Ge complex and InAs complex. However, the increment of shell thickness downregulated the sensitivity of nanowire [90]. Hence, a trade-off must be made between performance and long-term stability. Regardless, this strategy can significantly improve the long-term stability of the nanowires in complex environments, opening up the further investigation of using nanowire as a platform for in vivo injectable electronics [91]. On the other hand, cells can physically sense the nanowires in vivo, leading to certain concerns of nanowires' cytotoxicity and their effects on cell behavior. So far, the cell response to nanomaterials has not yet been systematically examined. Some preliminary studies indicate that nanowires do not significantly affect cell viability and proliferation [92]. On the contrary, more studies suggest that 1D nanostructures have a certain level of impact on cellular behavior, including cell viability, elongation, and differentiation [93]. For instance, Chen et al. reported a study on the toxicity of silicon carbide ( $\mathrm{SiC}$ ) nanowires, as shown in Figure 4B, and nanospheres on human mesenchymal stem cells (hMSCs) and cancer cells [94]. The impact of toxicity on metabolism, viability, proliferation, migration, oxidative stress, and differentiation potency were comprehensively examined. Interestingly, it was found that $\mathrm{SiC}$ nanowires are toxic to hMSCs, but not to breast cancer cell line MCF-7. The presence $\mathrm{SiC}$ nanowires, $200 \mathrm{~nm}$ in diameter, were seen to significantly reduce the adhesion and proliferation of hMSCs (Figure 4C) and to hamper their differentiation potency toward osteoblasts and adipocytes (Figure 4D). The toxicity is applied through the stress from altered morphology by nanowires, as proven by the significant changes of cytokine genes. Similarly, Alaraby et al. found that the Ni nanowire can cause DNA damage, gene alteration, and oxidative stress to cells, although the authors did not find a direct correlation between these negative effects to cytotoxicity and mutagenesis [95]. In summary, existing results suggest that the interaction between nanowires and cells is very sophisticated. It is, therefore, important for more research to be carried out in order to systematically understand and prevent the potential toxicity of nanowires during in vivo applications. 
A
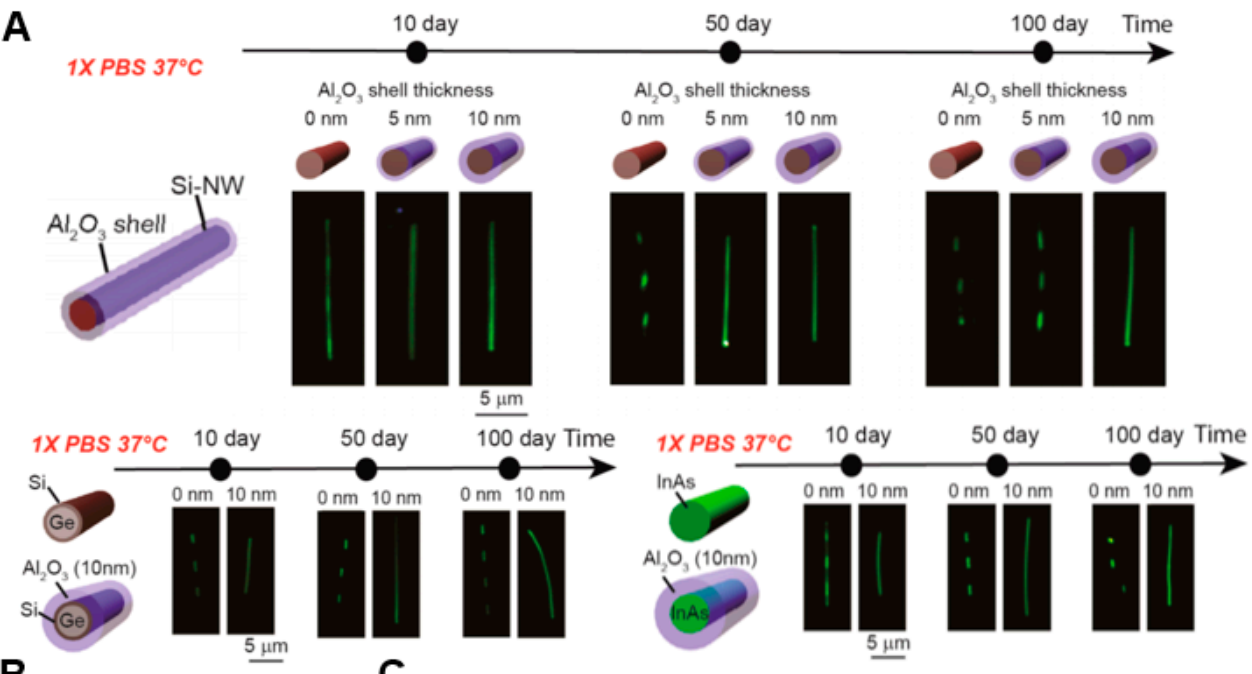

B

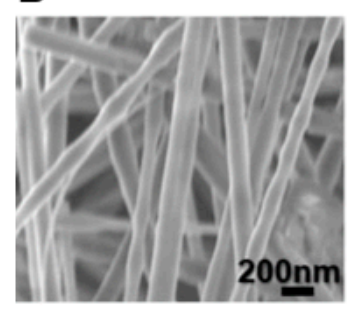

D

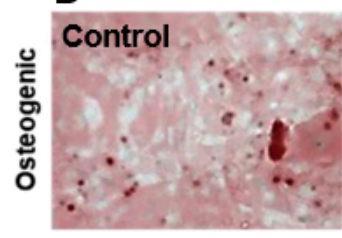

C
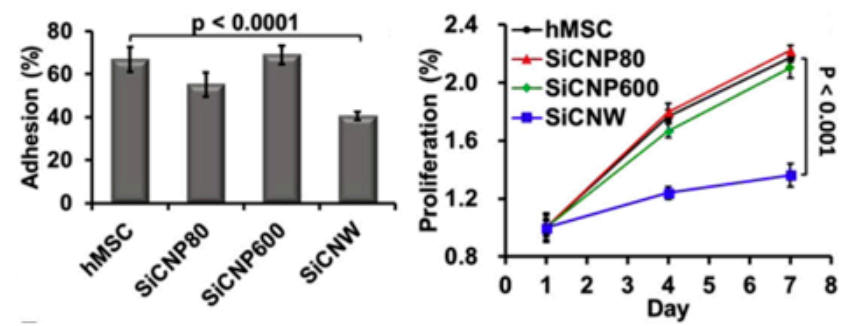

Figure 4. Design nanowires for in vivo sensing. (A) Improving long-term stability by $\mathrm{Al}_{2} \mathrm{O}_{3}$ shell coating (adopted with permission from [89]). (B-D) Cytotoxic effects of SiC nanowires to cell behavior and differentiation (adopted with permission from [89]). (B) SEM pictures of SiC nanowires.

(C) Quantification of adhesion and proliferation of hMSCs on nanowires and nanoparticles. (D) Quantification of differentiation potency of hMSCs on SiC nanowires. Alizarin Red S and Oil Red O stain was utilized to quantify the differentiation toward osteogenic and adipogenic lineage, respectively.

\subsection{Integration with Paper-Based Devices}

In addition to the traditional channel-based microfluidic devices, nanowires have recently been integrated with paper-based analytical devices (PADs) in order to facilitate biomarker detection in a portable fashion. The main advantages of PADs include low material and fabrication costs, as well as good biodegradability, as compared to silicon-based chips [96]. Li et al. reported a pioneering study using zinc oxide $(\mathrm{ZnO})$ nanowires in PADs for glucose detection [97]. They printed the whole PADs using a conductive ink (i.e., carbon ink) and used it as a substrate to grow $\mathrm{ZnO}$ nanowires from deposited $\mathrm{ZnO}$ nanoparticle (Figure $5 \mathrm{~A}$ ). The $\mathrm{ZnO}$ nanowires were grown in a low-temperature $\left(\sim 70{ }^{\circ} \mathrm{C}\right)$ hydrothermal manner. The hydrothermal method is compatible with mass-production setups and exhibits good control over the size of $\mathrm{ZnO}$ nanowires ( $300 \pm 50 \mathrm{~nm}$, Figure 5B). This may facilitate several downstream applications. The authors then demonstrated the application of this sensor by detecting glucose level. The sensor was found to have a LOD of $94.7 \mu \mathrm{M}$ and a linear range of up to $15 \mathrm{mM}$ (Figure 5C,D). Although this is not comparable to some traditional sensors that can go all the way down to a LOD of $0.5 \mu \mathrm{M}$, this sensor holds great potential for applications in remote biosensing. However, there are many critical issues that need to be addressed before implementation. Firstly, the detection of many proteins relies on the presence of enzymes. Preserving enzymes at room 
temperature for a long time is a key challenge needed to be addressed for the successful implementation of PADs with nanowires. Secondly, to have a smaller LOD, the high surface roughness that significantly hampers detection at low concentrations in PADs must be addressed (Figure 5B). Nanofibrillated cellulose (NFC) paper [98,99] has recently come up as a solution to provide nanometer level surface roughness that could potentially improve the LOD of ZnO PADs. Lastly, to fulfill the demand for remote sensing, it is important to make these devices wireless and power-free. This demand can be met by the self-powering technology discussed in the following section.
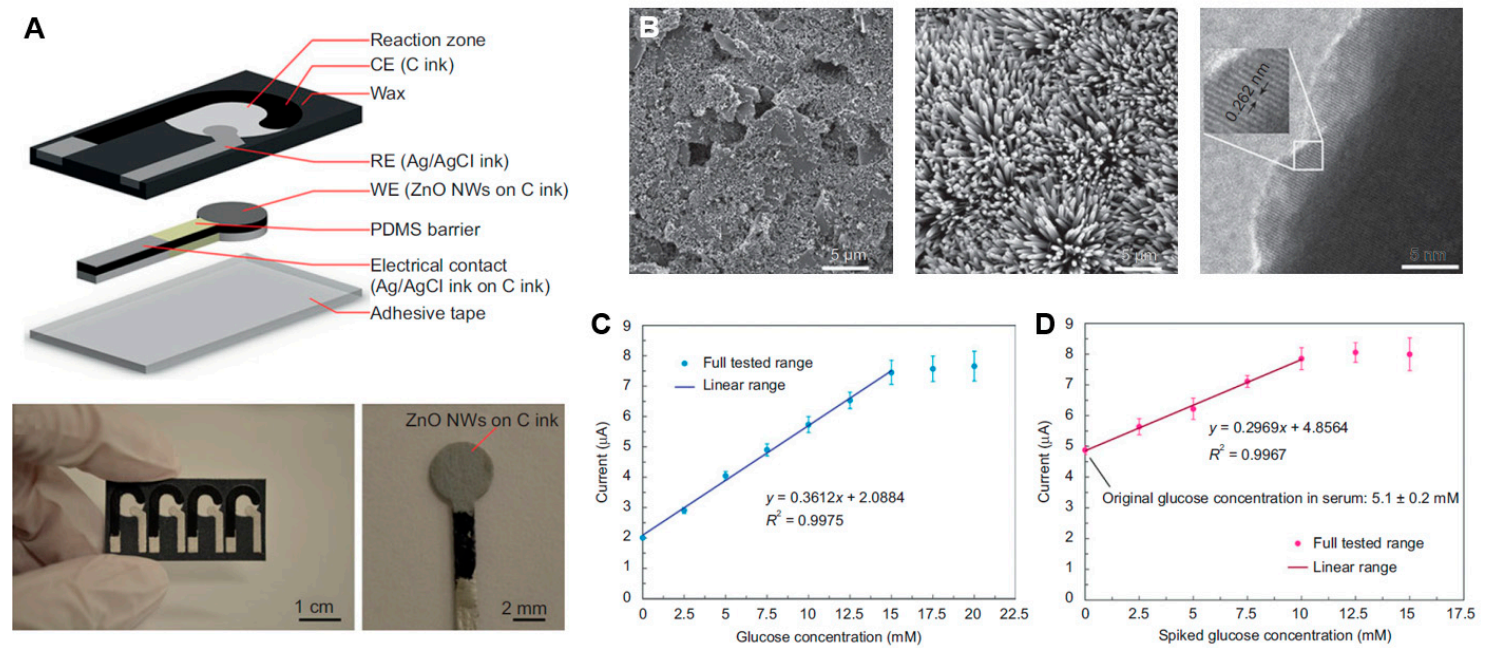

Figure 5. Integrate nanowires with disposable devices (adopted with permission from [97]). (A) Schematic and photograph of paper-based analytical devices (PADs) with $\mathrm{ZnO}$ nanowires. (B) Characterization of $\mathrm{ZnO}$ nanowires. From left to right: (1) SEM image of rough carbon surface before the growth of nanowire; (2) SEM image of nanostructured carbon surface with deposited ZnO nanowires; (3) TEM image for quantification of nanowires. (C) Calibration of sensor (output current vs. glucose concentration) in buffer. (D) Quantification of detected limits and linear range of the PADs in serum.

\subsection{Self-Powering}

The self-powering strategies can be divided on to two categories, those using triboelectric nanogenerators and others using biofuels. Since its discovery in 2006, the piezoelectric effect of $\mathrm{ZnO}$ nanowires has been widely applied to generate power for various devices [100]. In principle, by applying a mechanical force to a well-aligned, serially connected $\mathrm{ZnO}$ nanowire array, a 1.26-volt output voltage has been achieved, which is enough to power the nanowire-based $\mathrm{pH}$ sensor [101] and the wireless data transmission system [102]. However, the mechanical energy generated by significant physical motion is mostly limited to lung, muscle, and cardiac tissues in vivo $[103,104]$. Hence, biofuels are a more popular power source in vivo. Researchers have also examined glucose-mediated strategies like glucose $/ \mathrm{O}_{2}$ [105-107] and glucose/air for in vivo powering [108]. Additionally, Hansen et al. have demonstrated the potential of using a combination of piezoelectric effects and biofuels to build a self-powered system in vivo [109]. On the one hand, poly(vinylidene fluoride) nanofibers were utilized to harvest mechanical energy generated by the lung and heart (i.e., the breathing motion of the lung and the beating motion of the heart) while, on the other hand, biochemical energy was collected by a flexible enzymatic biofuel cell from biofluids. The synergetic effects of these two strategies lead to a higher output power and, potentially, a longer operating time.

\subsection{Signal Processing and Data Analysis}

Disease diagnostics usually involve the detection and analysis of multiple markers. Although there are many multiplexing biosensors being proposed, the majority of the research is still in the proof-of-concept stage, where the characterization of devices using spiked samples remains the 
gold standard. To fully claim the advantages of multivariable and multiplexing biosensors for practical diagnostics, signal processing techniques must be introduced to extract useful diagnostic information from the detected values. The idea of using signal processing for more meaningful data from nanowire sensor array originated from work in gas sensing [110]. For example, Cho et al. used a nanowire sensor array that consists of platinum, copper, indium, and nickel to detect vapors from explosive precursors including acetone, nitrobenzene, nitrotoluene, and octane [111]. They applied decision tree learning to classify the signals from the sensor array to predict the concentration of explosive precursors and access the risk of explosion with an accuracy beyond $90 \%$ and an error rate of less than 1\%. In 2016, Shehada et al. brought this concept to diagnostic applications by using an array of Si nanowires to detect the disease breathprints of cancers [112] (Figure 6A). In this study, they first fabricated functionalized the Si nanowires by a single-step or a two-step modification. The array was then characterized by a simulated breath from a mixture of eleven disease markers linked with gastric cancer (GC), lung cancer (LC), asthma, and chronic obstructive pulmonary disease (AC). Upon successful characterization, an artificial neural network (ANN) was built, where the sensing features are the inputs of the model, and the sample classification label is the output. The ANN was then trained by a dataset with sensing features and a known disease state under examination. The trained ANN, together with the array of nanowire biosensors, was applied to analyze the real patient breath $(n=374)$. It was found that the array with ANN could distinguish almost all binary comparison of disease with an accuracy higher than $80 \%$. However, the potential of machine learning is not fully realized in this study as the sample size is still limited, which results in poor accuracy rate (i.e., $~ 60 \%$ ) for specific diseases with limited samples. Following the study, a clinical big dataset of the exhaled molecules for 17 diseases was generated from 1404 subjects measured by nanobiosensors [113] (Figure 6B). This study revealed 13 new volatile organic compounds that were associated with certain diseases. The success of these clinical studies has demonstrated a great model to translate the potential of nanobiosensors from proof-of-concept experiments to practical clinical diagnostics. In addition, with advances in unsupervised deep learning [114], more information could be extracted from the arrayed data in an automated but accurate fashion.

A
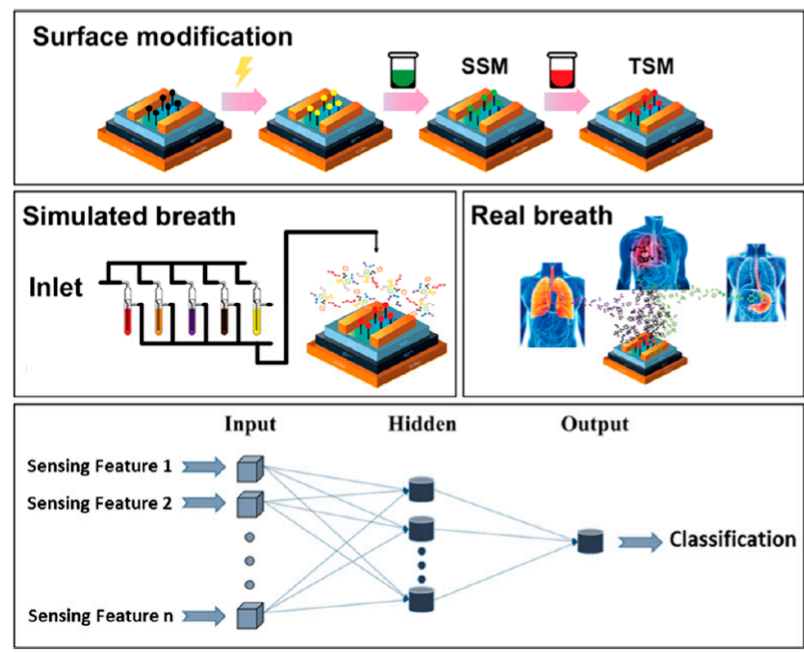

B

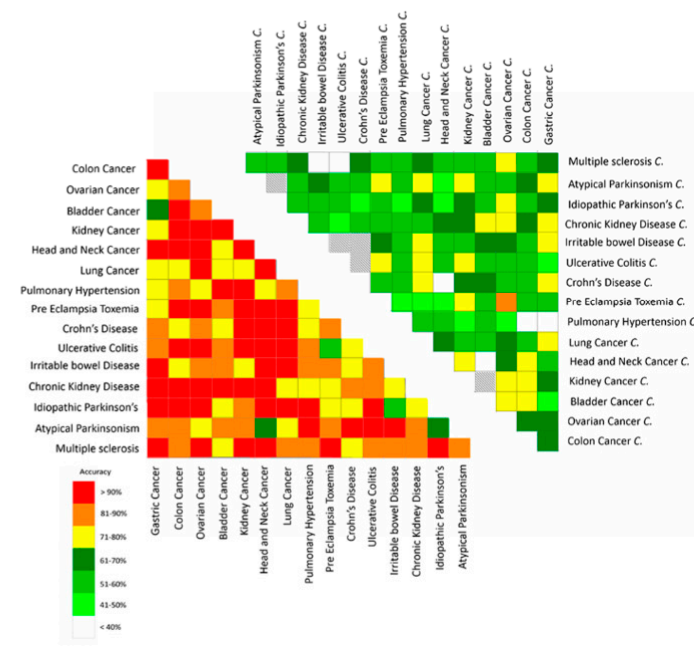

Figure 6. Signal processing strategy for multivariable nanowire biosensors. (A) Disease diagnostics based on machine learning: multivariable nanowire sensors were utilized to provide input for artificial neural networks (adopted with permission from [112]). (B) Big data strategy to correlate exhaled molecules detection by nanowire sensors with specific disease (adopted with permission from [113]). 


\section{Summary and Perspective}

With specific receptors, nanowire sensors have shown great potential to become a practical detection platform in biological and medical applications. The presented devices have several advantages, such as real-time transduction to electrical signal with high sensitivity and feasibility of label-free detection, as summarized in Table 1. In spite of these attractive features, some improvements are still required for commercialization. Even though its sensitivity is impressively high compared with other methods, its analytical signal intensity is still too low to be contaminated by high background noise, especially seen with in vivo environments. Improvements in receptor binding methods could resolve this higher sensitivity issue as well as more simple fabrication processing issues. In addition, a higher yield ratio of the current top-down fabrication methods enables a lower cost of commercialized products. Nevertheless, the success of a nanowire sensor will depend on how advanced it is compared with the current gold standards, such as PCR and ELISA, in terms of simplicity, sensitivity, specificity, and reliability. In particular, nanowire is expected to result in the development of promising wearable biosensors [115-119].

Table 1. Summary of the salient features and the target application of nanowire-based biosensors.

\begin{tabular}{llc}
\hline Features & Application & Reference \\
\hline Top-down fabrication process using SCS wafer & $\begin{array}{l}\text { Photodiode and FET for the retinal } \\
\text { prosthetic systems }\end{array}$ & {$[52,53]$} \\
High sensitivity using PEG cross-linker & Detection of protein and DNA & {$[62]$} \\
Long-term stability using $\mathrm{Al}_{2} \mathrm{O}_{3}$ shell coating & In vivo sensing & {$[89]$} \\
Integrating nanowires with disposable device & Glucose detection & {$[97]$} \\
Multivariable detection using machine learning & Multiple disease diagnosis & {$[112,113]$} \\
\hline
\end{tabular}

Funding: This research was supported by the National Research Foundation of Korea (NRF) (NRF-2015M3A7B7046616, and NRF-2017M3A9E2062707), and supported by a Natural Sciences and Engineering Research Council of Canada (NSERC) Discovery Grant (RGPIN-2014-04010) and Canada Foundation for Innovation John R. Evans Leaders Opportunity Fund.

Conflicts of Interest: The authors declare no conflict of interest.

\section{References}

1. Etzioni, R.; Urban, N.; Ramsey, S.; McIntosh, M.; Schwartz, S.; Reid, B.; Radich, J.; Anderson, G.; Hartwell, L. The case for early detection. Nat. Rev. Cancer 2003, 3, 243-252. [CrossRef]

2. Burrell, R.A.; McGranahan, N.; Bartek, J.; Swanton, C. The causes and consequences of genetic heterogeneity in cancer evolution. Nature 2013, 501, 338-345. [CrossRef] [PubMed]

3. Wulfkuhle, J.D.; Liotta, L.A.; Petricoin, E.F. Proteomic applications for the early detection of cancer. Nat. Rev. Cancer 2003, 3, 267-275. [CrossRef] [PubMed]

4. Adam, T.; Hashim, U. Highly sensitive silicon nanowire biosensor with novel liquid gate control for detection of specific single-stranded DNA molecules. Biosens. Bioelectron. 2015, 67, 656-661. [CrossRef] [PubMed]

5. Kim, K.; Park, C.; Kwon, D.; Kim, D.; Meyyappan, M.; Jeon, S.; Lee, J.-S. Silicon nanowire biosensors for detection of cardiac troponin I (cTnI) with high sensitivity. Biosens. Bioelectron. 2016, 77, 695-701. [CrossRef] [PubMed]

6. Patolsky, F.; Zheng, G.; Lieber, C.M. Nanowire sensors for medicine and the life sciences. Nanomedicine 2006, 1, 51-65. [CrossRef] [PubMed]

7. Poole; Owens, F.J. Introduction to Nanotechnology; Wiley: Hoboken, NJ, USA, 2003.

8. Wang, Y.; Herron, N. Nanometer-Sized Semiconductor Clusters: Materials Synthesis, Quantum Size Effects, and Photophysical Properties. J. Phys. Chem. 1991, 95, 525-532. [CrossRef]

9. Lee, W.; Ko, H.; Cho, D.D.; Koo, K.; Seo, J. A Review of Nanotechnology for Highly Sensitive Photodetectors for Vision Sensors of Insect-like Robots. Sens. Mater. 2015, 27, 465-474. [CrossRef]

10. Kurkina, T.; Balasubramanian, K. Towards in vitro molecular diagnostics using nanostructures. Cell. Mol. Life Sci. 2012, 69, 373-388. [CrossRef] 
11. Alivisatos, P. The use of nanocrystals in biological detection. Nat. Biotechnol. 2004, 22, 47-52. [CrossRef]

12. Ballou, B.; Lagerholm, B.C.; Ernst, L.A.; Bruchez, M.P.; Waggoner, A.S. Noninvasive Imaging of Quantum Dots in Mice. Bioconjugate Chem. 2004, 15, 79-86. [CrossRef] [PubMed]

13. Jaffer, F.A.; Weissleder, R. Seeing Within: Molecular Imaging of the Cardiovascular System. Circ. Res. 2004, 94, 433-445. [CrossRef] [PubMed]

14. Perez, J.M.; Josephson, L.; Weissleder, R. Use of magnetic nanoparticles as nanosensors to probe for molecular interactions. ChemBioChem 2004, 5, 261-264. [CrossRef] [PubMed]

15. Sang, S.; Wang, Y.; Feng, Q.; Wei, Y.; Ji, J.; Zhang, W. Progress of new label-free techniques for biosensors: A review. Crit. Rev. Biotechnol. 2015, 36, 465-481. [CrossRef] [PubMed]

16. Cui, Y.; Wei, Q.; Park, H.; Lieber, C.M. Nanowire nanosensors for highly sensitive and selective detection of biological and chemical species. Science 2001, 293, 1289-1292. [CrossRef] [PubMed]

17. Seker, F.; Meeker, K.; Kuech, T.F.; Ellis, A.B. Surface chemistry of prototypical bulk II-VI and III-V semiconductors and implications for chemical sensing. Chem. Rev. 2000, 100, 2505-2536. [CrossRef] [PubMed]

18. Taylor, R.F.; Schultz, J.S. Handbook of Chemical and Biological Sensors; Institute of Physics Pub.: Washington, DC, USA, 1996.

19. Cui, Y.; Zhong, Z.H.; Wang, D.L.; Wang, W.U.; Lieber, C.M. High performance silicon nanowire field effect transistors. Nano Lett. 2003, 3, 149-152. [CrossRef]

20. Lieber, C.M. The incredible shrinking circuit-Researchers have built nanotransistors and nanowires. Now they just need to find a way to put them all together. Sci. Am. 2001, 285, 58-64. [CrossRef]

21. Ajayan, P.M.; Tour, J.M. Nanotube composites. Nature 2007, 447, 1066-1068. [CrossRef]

22. Zhang, G.J.; Ning, Y. Silicon nanowire biosensor and its applications in disease diagnostics: A review. Anal. Chim. Acta 2012, 749, 1-15. [CrossRef]

23. Kaushik, A.; Kumar, R.; Huey, E.; Bhansali, S.; Nair, N.; Nair, M. Silica nanowires: Growth, integration, and sensing applications. Microchim. Acta 2014, 181, 1759-1780. [CrossRef]

24. Wang, Z.; Lee, S.; Koo, K.; Kim, K. Nanowire-Based Sensors for Biological and Medical Applications. IEEE Trans. Nanobiosci. 2016, 15, 186-199. [CrossRef] [PubMed]

25. Lee, S.; Koo, K.; Ko, H.; Seo, J.-M.; Cho, D.D. Review of High-resolution Retinal Prosthetic System for Vision Rehabilitation: Our Perspective Based on 18 Years of Research. Sens. Mater. 2018, 30, 1393. [CrossRef]

26. Sze, S.M. Physics of Semiconductor Devices, 2nd ed.; Wiley: New York, NY, USA, 1981.

27. Bergveld, P. Development, operation, and application of the ion-sensitive field-effect transistor as a tool for electrophysiology. IEEE Trans. Biomed. Eng. 1972, 19, 342-351. [CrossRef] [PubMed]

28. Lieber, C.M. Nanoscale Science and Technology: Building a Big Future from Small Things. MRS Bull. 2003, 28, 486-491. [CrossRef]

29. Wu, Y.; Xiang, J.; Yang, C.; Lu, W.; Lieber, C.M. Single-crystal metallic nanowires and metal/semiconductor nanowire heterostructures. Nature 2004, 430, 61-65. [CrossRef] [PubMed]

30. Zheng, G.; Lu, W.; Jin, S.; Lieber, C.M. Synthesis and fabrication of high-performance n-type silicon nanowire transistors. Adv. Mater. 2004, 16, 1890-1893. [CrossRef]

31. Patolsky, F.; Zheng, G.; Lieber, C.M. Fabrication of silicon nanowire devices for ultrasensitive, label-free, real-time detection of biological and chemical species. Nat. Protoc. 2006, 1, 1711-1724. [CrossRef] [PubMed]

32. Patolsky, F.; Zheng, G.; Hayden, O.; Lakadamyali, M.; Zhuang, X.; Lieber, C.M. Electrical detection of single viruses. Proc. Natl. Acad. Sci. USA 2004, 101, 14017-14022. [CrossRef]

33. Zheng, G.; Patolsky, F.; Cui, Y.; Wang, W.U.; Lieber, C.M. Multiplexed electrical detection of cancer markers with nanowire sensor arrays. Nat. Biotechnol. 2005, 23, 1294-1301. [CrossRef]

34. McAlpine, M.C.; Ahmad, H.; Wang, D.; Heath, J.R. Highly ordered nanowire arrays on plastic substrates for ultrasensitive flexible chemical sensors. Nat. Mater. 2007, 6, 379-384. [CrossRef] [PubMed]

35. Poghossian, A.; Cherstvy, A.; Ingebrandt, S.; Offenhäusser, A.; Schöning, M.J. Possibilities and limitations of label-free detection of DNA hybridization with field-effect-based devices. Sens. Actuators B Chem. 2005, 111-112, 470-480. [CrossRef]

36. Ghatak, K.P.; Bhattacharya, S. Debye Screening Length Effects of Nanostructured Materials; Springer International Publishing: New York, NY, USA, 2014; ISBN 9783319013381. 
37. Poghossian, A.; Weil, M.; Cherstvy, A.G.; Schöning, M.J. Electrical monitoring of polyelectrolyte multilayer formation by means of capacitive field-effect devices. Anal. Bioanal. Chem. 2013, 405, 6425-6436. [CrossRef] [PubMed]

38. Yang, F.; Zhang, G.-J. Silicon nanowire-transistor biosensor for study of molecule-molecule interactions. Rev. Anal. Chem. 2014, 33, 95-110. [CrossRef]

39. Stern, E.; Wagner, R.; Sigworth, F.J.; Breaker, R.; Fahmy, T.M.; Reed, M.A. Importance of the debye screening length on nanowire field effect transistor sensors. Nano Lett. 2007, 7, 3405-3409. [CrossRef] [PubMed]

40. Baraban, L.; Zörgiebel, F.; Pahlke, C.; Baek, E. Nanowire Field Effect Transistors: Principles and Applications; Springer International Publishing: New York, NY, USA, 2014; ISBN 978-1-4614-8123-2.

41. Li, C.P.; Lee, C.S.; Ma, X.L.; Wang, N.; Zhang, R.Q.; Lee, S.T. Growth Direction and Cross-Sectional Study of Silicon Nanowires. Adv. Mater. 2003, 15, 607-609. [CrossRef]

42. Wagner, R.S.; Ellis, W.C. Vapor-Liquid-Solid Mechanism of Single Crystal Growth. Appl. Phys. Lett. 1964, 4, 89. [CrossRef]

43. Whang, D.; Jin, S.; Wu, Y.; Lieber, C.M. Large-scale hierarchical organization of nanowire arrays for integrated nanosystems. Nano Lett. 2003, 3, 1255-1259. [CrossRef]

44. Yu, G.; Cao, A.; Lieber, C.M. Large-area blown bubble films of aligned nanowires and carbon nanotubes. Nat. Nanotechnol. 2007, 2, 372-377. [CrossRef]

45. Huang, Y.; Duan, X.; Wei, Q.; Lieber, C.M. Directed assembly of one-dimensional nanostructures into functional networks. Science 2001, 291, 630-633. [CrossRef]

46. Fan, Z.; Ho, J.C.; Jacobson, Z.A.; Yerushalmi, R.; Alley, R.L.; Razavi, H.; Javey, A. Wafer-scale assembly of highly ordered semiconductor nanowire arrays by contact printing. Nano Lett. 2008, 8, 20-25. [CrossRef] [PubMed]

47. Li, M.; Bhiladvala, R.B.; Morrow, T.J.; Sioss, J.A.; Lew, K.-K.; Redwing, J.M.; Keating, C.D.; Mayer, T.S. Bottom-up assembly of large-area nanowire resonator arrays. Nat. Nanotechnol. 2008, 3, 88-92. [CrossRef] [PubMed]

48. Freer, E.M.; Grachev, O.; Duan, X.; Martin, S.; Stumbo, D.P. High-yield self-limiting single-nanowire assembly with dielectrophoresis. Nat. Nanotechnol. 2010, 5, 525-530. [CrossRef] [PubMed]

49. Vu, X.T.; Eschermann, J.F.; Stockmann, R.; Ghoshmoulick, R.; Offenhäusser, A.; Ingebrandt, S. Top-down processed silicon nanowire transistor arrays for biosensing. Phys. Status Solidi Appl. Mater. Sci. 2009, 206, 426-434. [CrossRef]

50. Vu, X.T.; GhoshMoulick, R.; Eschermann, J.F.; Stockmann, R.; Offenhäusser, A.; Ingebrandt, S. Fabrication and application of silicon nanowire transistor arrays for biomolecular detection. Sens. Actuators B Chem. 2010, 144, 354-360. [CrossRef]

51. Lee, K.-N.; Jung, S.-W.; Shin, K.-S.; Kim, W.-H.; Lee, M.-H.; Seong, W.-K. Fabrication of Suspended Silicon Nanowire Arrays. Small 2008, 4, 642-648. [CrossRef] [PubMed]

52. Lee, S.; Jung, S.W.; Park, S.; Ahn, J.; Hong, S.J.; Yoo, H.J.; Lee, M.H.; Cho, D.I. Fabrication and Evaluation of Silicon Nanowire Photodetectors on Flexible Substrate for Retinal Prosthetic System. Sens. Mater. 2012, 24, 205-220. [CrossRef]

53. Lee, S.; Jung, S.W.; Ahn, J.; Yoo, H.J.; Oh, S.J. Microelectrode array with integrated nanowire FET switches for high-resolution retinal prosthetic systems. J. Micromech. Microeng. 2014, 24, 075018. [CrossRef]

54. Wang, Z.; Samanipour, R.; Kim, K. Organ-on-a-Chip Platforms for Drug Screening and Tissue Engineering. In Biomedical Engineering: Frontier Research and Converging Technologies; Springer International Publishing: New York, NY, USA, 2015; pp. 209-233.

55. Wang, Z.; Samanipour, R.; Koo, K.; Kim, K. Organ-on-a-Chip Platforms for Drug Delivery and Cell Characterization: A Review. Sens. Mater. 2015, 27, 487-506.

56. Chua, J.H.; Chee, R.E.; Agarwal, A.; She, M.W.; Zhang, G.J. Label-free electrical detection of cardiac biomarker with complementary metal-oxide semiconductor-compatible silicon nanowire sensor arrays. Anal. Chem. 2009, 81, 6266-6271. [CrossRef] [PubMed]

57. Puppo, F.; Doucey, M.A.; Delaloye, J.F.; Moh, T.S.Y.; Pandraud, G.; Sarro, P.M.; De Micheli, G.; Carrara, S. SiNW-FET in-Air Biosensors for High Sensitive and Specific Detection in Breast Tumor Extract. IEEE Sens. J. 2016, 16, 3374-3381. [CrossRef] 
58. Lin, Z.; Li, Y.; Gu, J.; Wang, H.; Zhu, Z.; Hong, X.; Zhang, Z.; Lu, Q.; Qiu, J.; Wang, X.; et al. A Conductive Nanowire-Mesh Biosensor for Ultrasensitive Detection of Serum C-Reactive Protein in Melanoma. Adv. Funct. Mater. 2018, 1802482, 1-9. [CrossRef]

59. Kim, A.; Ah, C.S.; Yu, H.Y.; Yang, J.H.; Baek, I.B.; Ahn, C.G.; Park, C.W.; Jun, M.S.; Lee, S. Ultrasensitive, label-free, and real-time immunodetection using silicon field-effect transistors. Appl. Phys. Lett. 2007, 91, 29-32. [CrossRef]

60. Stern, E.; Vacic, A.; Rajan, N.K.; Criscione, J.M.; Park, J.; Fahmy, T.M.; Reed, M.A. Label-free biomarker detection from whole blood. Nat. Nanotechnol. 2010, 5, 138-142. [CrossRef] [PubMed]

61. Luo, X.; Davis, J.J. Electrical biosensors and the label free detection of protein disease biomarkers. Chem. Soc. Rev. 2013, 42, 5944-5962. [CrossRef] [PubMed]

62. Janissen, R.; Sahoo, P.K.; Santos, C.A.; Da Silva, A.M.; Von Zuben, A.A.G.; Souto, D.E.P.; Costa, A.D.T.; Celedon, P.; Zanchin, N.I.T.; Almeida, D.B.; et al. InP Nanowire Biosensor with Tailored Biofunctionalization: Ultrasensitive and Highly Selective Disease Biomarker Detection. Nano Lett. 2017, 17, 5938-5949. [CrossRef] [PubMed]

63. Zhang, G.; Zhang, G.; Chua, J.H.; Chee, R.; Wong, E.H.; Buddharaju, K.D.; Singh, N.; Gao, Z.; Balasubramanian, N. DNA Sensing by Silicon Nanowire: Charge Layer Distance Dependence. Nano 2008, 8 , 1066-1070. [CrossRef]

64. Wu, C.C.; Ko, F.H.; Yang, Y.S.; Hsia, D.L.; Lee, B.S.; Su, T.S. Label-free biosensing of a gene mutation using a silicon nanowire field-effect transistor. Biosens. Bioelectron. 2009, 25, 820-825. [CrossRef]

65. Hahm, J.; Lieber, C.M. Direct Ultrasensitive Electrical Detection of DNA and DNA Sequence Variations Using Nanowire Nanosensors. Nano Lett. 2004, 4, 51-54. [CrossRef]

66. Höök, F.; Ray, A.; Nordén, B.; Kasemo, B. Characterization of PNA and DNA immobilization and subsequent hybridization with DNA using acoustic-shear-wave attenuation measurements. Langmuir 2001, 17, 8305-8312. [CrossRef]

67. Kilså Jensen, K.; Ørum, H.; Nielsen, P.E.; Nordén, B. Kinetics for hybridization of peptide nucleic acids (PNA) with DNA and RNA studied with the BIAcore technique. Biochemistry 1997, 36, 5072-5077. [CrossRef] [PubMed]

68. He, L.; Musick, M.D.; Nicewarner, S.R.; Salinas, F.G.; Benkovic, S.J.; Natan, M.J.; Keating, C.D. Colloidal Au-enhanced surface plasmon resonance for ultrasensitive detection of DNA hybridization. J. Am. Chem. Soc. 2000, 122, 9071-9077. [CrossRef]

69. Zhang, G.J.; Huang, M.J.; Ang, J.J.; Liu, E.T.; Desai, K.V. Self-assembled monolayer-assisted silicon nanowire biosensor for detection of protein-DNA interactions in nuclear extracts from breast cancer cell. Biosens. Bioelectron. 2011, 26, 3233-3239. [CrossRef] [PubMed]

70. Zhang, G.J.; Huang, M.J.; Ang, J.J.; Yao, Q.; Ning, Y. Label-free detection of carbohydrate-protein interactions using nanoscale field-effect transistor biosensors. Anal. Chem. 2013, 85, 4392-4397. [CrossRef] [PubMed]

71. Lu, N.; Gao, A.; Dai, P.; Song, S.; Fan, C.; Wang, Y.; Li, T. CMOS-compatible silicon nanowire field-effect transistors for ultrasensitive and label-free microRNAs sensing. Small 2014, 10, 2022-2028. [CrossRef] [PubMed]

72. Huang, Y.L.; Gao, Z.F.; Luo, H.Q.; Li, N.B. Sensitive detection of HIV gene by coupling exonuclease III-assisted target recycling and guanine nanowire amplification. Sens. Actuators B Chem. 2017, 238, 1017-1023. [CrossRef]

73. Gao, A.; Yang, X.; Tong, J.; Zhou, L.; Wang, Y.; Zhao, J.; Mao, H.; Li, T. Multiplexed detection of lung cancer biomarkers in patients serum with CMOS-compatible silicon nanowire arrays. Biosens. Bioelectron. 2017, 91, 482-488. [CrossRef]

74. Yasui, T.; Yanagida, T.; Ito, S.; Konakade, Y.; Takeshita, D.; Naganawa, T.; Nagashima, K.; Shimada, T.; Kaji, N.; Nakamura, Y.; et al. Unveiling massive numbers of cancer-related urinary-microRNA candidates via nanowires. Sci. Adv. 2017, 3, e1701133. [CrossRef]

75. Doucey, M.A.; Carrara, S. Nanowire Sensors in Cancer. Trends Biotechnol. 2018, 1-14. [CrossRef]

76. Stadler, K.; Masignani, V.; Eickmann, M.; Becker, S.; Abrignani, S.; Klenk, H.-D.; Rappuoli, R. SARS-beginning to understand a new virus. Nat. Rev. Microbiol. 2003, 1, 209-218. [CrossRef]

77. Atlas, R.M. Bioterrorism and biodefence research: Changing the focus of microbiology. Nat. Rev. Microbiol. 2003, 1, 70-74. [CrossRef] [PubMed] 
78. Zhang, G.-J.; Zhang, L.; Huang, M.J.; Luo, Z.H.H.; Tay, G.K.I.; Lim, E.-J.A.; Kang, T.G.; Chen, Y. Silicon nanowire biosensor for highly sensitive and rapid detection of Dengue virus. Sens. Actuators B Chem. 2010, 146, 138-144. [CrossRef]

79. Shen, F.; Wang, J.; Xu, Z.; Wu, Y.; Chen, Q.; Li, X.; Jie, X.; Li, L.; Yao, M.; Guo, X.; et al. Rapid flu diagnosis using silicon nanowire sensor. Nano Lett. 2012, 12, 3722-3730. [CrossRef] [PubMed]

80. Kao, L.T.H.; Shankar, L.; Kang, T.G.; Zhang, G.; Tay, G.K.I.; Rafei, S.R.M.; Lee, C.W.H. Multiplexed detection and differentiation of the DNA strains for influenza A (H1N1 2009) using a silicon-based microfluidic system. Biosens. Bioelectron. 2011, 26, 2006-2011. [CrossRef]

81. Inci, F.; Tokel, O.; Wang, S.; Gurkan, U.A.; Tasoglu, S.; Kuritzkes, D.R.; Demirci, U. Nanoplasmonic quantitative detection of intact viruses from unprocessed whole blood. ACS Nano 2013, 7, 4733-4745. [CrossRef] [PubMed]

82. Ibarlucea, B.; Akbar, T.F.; Kim, K.; Rim, T.; Baek, C.K.; Ascoli, A.; Tetzlaff, R.; Baraban, L.; Cuniberti, G. Ultrasensitive detection of Ebola matrix protein in a memristor mode. Nano Res. 2018, 11, 1057-1068. [CrossRef]

83. Zhou, W.; Dai, X.; Lieber, C.M. Advances in nanowire bioelectronics. Rep. Prog. Phys. 2017, 80, 016701. [CrossRef] [PubMed]

84. Xie, C.; Liu, J.; Fu, T.M.; Dai, X.; Zhou, W.; Lieber, C.M. Three-dimensional macroporous nanoelectronic networks as minimally invasive brain probes. Nat. Mater. 2015, 14, 1286-1292. [CrossRef]

85. Cui, Y.; Lauhon, L.J.; Gudiksen, M.S.; Wang, J.; Lieber, C.M. Diameter-controlled synthesis of single-crystal silicon nanowires. Appl. Phys. Lett. 2001, 78, 2214-2216. [CrossRef]

86. Ahn, S.; Spuhler, P.S.; Chiari, M.; Cabodi, M.; Selim Ünlü, M. Quantification of surface etching by common buffers and implications on the accuracy of label-free biological assays. Biosens. Bioelectron. 2012, 36, $222-229$. [CrossRef]

87. Tian, B.; Liu, J.; Dvir, T.; Jin, L.; Tsui, J.H.; Qing, Q.; Suo, Z.; Langer, R.; Kohane, D.S.; Lieber, C.M. Macroporous nanowire nanoelectronic scaffolds for synthetic tissues. Nat. Mater. 2012, 11, 986-994. [CrossRef]

88. Hwang, S.-W.; Tao, H.; Kim, D.-H.; Cheng, H.; Song, J.-K.; Rill, E.; Brenckle, M.A.; Panilaitis, B.; Won, S.M.; Kim, Y.-S.; et al. A Physically Transient Form of Silicon Electronics. Science 2012, 337, 1640-1644. [CrossRef] [PubMed]

89. Zhou, W.; Dai, X.; Fu, T.; Xie, C.; Liu, J.; Lieber, C.M. Long Term Stability of Nanowire Nanoelectronics in Physiological Environments. Nano Lett. 2014, 14, 1614-1619. [CrossRef]

90. Peled, A.; Pevzner, A.; Peretz Soroka, H.; Patolsky, F. Morphological and chemical stability of silicon nanostructures and their molecular overlayers under physiological conditions: Towards long-term implantable nanoelectronic biosensors. J. Nanobiotechnol. 2014, 12, 7. [CrossRef]

91. Liu, J.; Fu, T.-M.; Cheng, Z.; Hong, G.; Zhou, T.; Jin, L.; Duvvuri, M.; Jiang, Z.; Kruskal, P.; Xie, C.; et al. Syringe-injectable electronics. Nat. Nanotechnol. 2015, 10, 629-636. [CrossRef] [PubMed]

92. Cacchioli, A.; Ravanetti, F.; Alinovi, R.; Pinelli, S.; Rossi, F.; Negri, M.; Bedogni, E.; Campanini, M.; Galetti, M.; Goldoni, M.; et al. Cytocompatibility and cellular internalization mechanisms of $\mathrm{SiC} / \mathrm{SiO}_{2}$ nanowires. Nano Lett. 2014, 14, 4368-4375. [CrossRef]

93. Poudineh, M.; Wang, Z.; Labib, M.; Ahmadi, M.; Zhang, L.; Das, J.; Ahmed, S.U.; Angers, S.; Kelley, S.O. Three-Dimensional Nanostructured Architectures Enable Efficient Neural Differentiation of Mesenchymal Stem Cells via Mechanotransduction. Nano Lett. 2018, 18, 7188-7193. [CrossRef]

94. Chen, F.; Li, G.; Zhao, E.R.; Li, J.; Hableel, G.; Lemaster, J.E.; Bai, Y.; Sen, G.L.; Jokerst, J.V. Cellular toxicity of silicon carbide nanomaterials as a function of morphology. Biomaterials 2018, 179, 60-70. [CrossRef]

95. Alaraby, M.; Hernández, A.; Marcos, R. Systematic in vivo study of $\mathrm{NiO}$ nanowires and nanospheres: Biodegradation, uptake and biological impacts. Nanotoxicology 2018, 12, 1-18. [CrossRef] [PubMed]

96. Song, P.; Wang, Y.H.; Liu, X. Flexible physical sensors made from Paper substrates integrated with zinc oxide nanostructures. Flex. Print. Electron. 2017, 2, 034001. [CrossRef]

97. Li, X.; Zhao, C.; Liu, X. A paper-based microfluidic biosensor integrating zinc oxide nanowires for electrochemical glucose detection. Microsyst. Nanoeng. 2015, 1, 15014. [CrossRef]

98. Kalia, S.; Boufi, S.; Celli, A.; Kango, S. Nanofibrillated cellulose: Surface modification and potential applications. Colloid Polym. Sci. 2014, 292, 5-31. [CrossRef]

99. Missoum, K.; Belgacem, M.N.; Bras, J. Nanofibrillated cellulose surface modification: A review. Materials 2013, 6, 1745-1766. [CrossRef] [PubMed] 
100. Wang, Z.L.; Song, J. Piezoelectric Nanogenerators Based on Zinc Oxide Nanowire Arrays. Science 2006, 312, 242-246. [CrossRef] [PubMed]

101. Xu, S.; Qin, Y.; Xu, C.; Wei, Y.; Yang, R.; Wang, Z.L. Self-powered nanowire devices. Nat. Nanotechnol. 2010, 5, 366-373. [CrossRef] [PubMed]

102. Hu, Y.; Zhang, Y.; Xu, C.; Lin, L.; Snyder, R.L.; Wang, Z.L. Self-Powered System with Wireless Data Transmission. Nano Lett. 2011, 11, 2572-2577. [CrossRef] [PubMed]

103. Cao, R.; Wang, J.; Zhao, S.; Yang, W.; Yuan, Z.; Yin, Y.; Du, X.; Li, N.W.; Zhang, X.; Li, X.; et al. Self-powered nanofiber-based screen-print triboelectric sensors for respiratory monitoring. Nano Res. 2018, 11, 3771-3779. [CrossRef]

104. Chen, B.D.; Tang, W.; He, C.; Jiang, T.; Xu, L.; Zhu, L.P.; Gu, G.Q.; Chen, J.; Shao, J.J.; Luo, J.J.; et al. Ultrafine Capillary-Tube Triboelectric Nanogenerator as Active Sensor for Microliquid Biological and Chemical Sensing. Adv. Mater. Technol. 2018, 3, 1-10. [CrossRef]

105. Yan, Y.; Zheng, W.; Su, L.; Mao, L. Carbon-nanotube-based glucose/O 2 biofuel cells. Adv. Mater. 2006, 18, 2639-2643. [CrossRef]

106. Yang, L.; Zhang, Y.; Chu, M.; Deng, W.; Tan, Y.; Ma, M.; Su, X.; Xie, Q.; Yao, S. Facile fabrication of network film electrodes with ultrathin Au nanowires for nonenzymatic glucose sensing and glucose $/ \mathrm{O}_{2}$ fuel cell. Biosens. Bioelectron. 2014, 52, 105-110. [CrossRef]

107. Haddad, R.; Thery, J.; Gauthier-Manuel, B.; Elouarzaki, K.; Holzinger, M.; Le Goff, A.; Gautier, G.; El Mansouri, J.; Martinent, A.; Cosnier, S. High performance miniature glucose $/ \mathrm{O}_{2}$ fuel cell based on porous silicon anion exchange membrane. Electrochem. Commun. 2015, 54, 10-13. [CrossRef]

108. Zhao, M.; Gao, Y.; Sun, J.; Gao, F. Mediatorless Glucose Biosensor and Direct Electron Transfer Type Glucose/Air Biofuel Cell Enabled with Carbon Nanodots. Anal. Chem. 2015, 87, 2615-2622. [CrossRef] [PubMed]

109. Hansen, B.J.; Liu, Y.; Yang, R.; Wang, Z.L. Hybrid Nanogenerator for Concurrently Biomedical and Biochemical Energy. ACS Nano 2010, 4, 3647-3652. [CrossRef] [PubMed]

110. Potyrailo, R.A. Multivariable Sensors for Ubiquitous Monitoring of Gases in the Era of Internet of Things and Industrial Internet. Chem. Rev. 2016, 116, 11877-11923. [CrossRef] [PubMed]

111. Cho, J.; Li, X.; Gu, Z.; Kurup, P.U. Recognition of explosive precursors using nanowire sensor array and decision tree learning. IEEE Sens. J. 2012, 12, 2384-2391. [CrossRef]

112. Shehada, N.; Cancilla, J.C.; Torrecilla, J.S.; Pariente, E.S.; Brönstrup, G.; Christiansen, S.; Johnson, D.W.; Leja, M.; Davies, M.P.A.; Liran, O.; et al. Silicon Nanowire Sensors Enable Diagnosis of Patients via Exhaled Breath. ACS Nano 2016, 10, 7047-7057. [CrossRef] [PubMed]

113. Nakhleh, M.K.; Amal, H.; Jeries, R.; Broza, Y.Y.; Aboud, M.; Gharra, A.; Ivgi, H.; Khatib, S.; Badarneh, S.; Har-Shai, L.; et al. Diagnosis and Classification of 17 Diseases from 1404 Subjects via Pattern Analysis of Exhaled Molecules. ACS Nano 2017, 11, 112-125. [CrossRef] [PubMed]

114. Silver, D.; Schrittwieser, J.; Simonyan, K.; Antonoglou, I.; Huang, A.; Guez, A.; Hubert, T.; Baker, L.; Lai, M.; Bolton, A.; et al. Mastering the game of Go without human knowledge. Nature 2017, 550, 354-359. [CrossRef]

115. Liu, Q.; Liu, Y.; Wu, F.; Cao, X.; Li, Z.; Alharbi, M.; Abbas, A.N.; Amer, M.R.; Zhou, C. Highly Sensitive and Wearable $\mathrm{In}_{2} \mathrm{O}_{3}$ Nanoribbon Transistor Biosensors with Integrated On-Chip Gate for Glucose Monitoring in Body Fluids. ACS Nano 2018, 12, 1170-1178. [CrossRef]

116. Kim, J.; Sempionatto, J.R.; Imani, S.; Hartel, M.C.; Barfidokht, A.; Tang, G.; Campbell, A.S.; Mercier, P.P.; Wang, J. Simultaneous Monitoring of Sweat and Interstitial Fluid Using a Single Wearable Biosensor Platform. Adv. Sci. 2018, 5, 1800880. [CrossRef]

117. Mishra, R.K.; Hubble, L.J.; Martín, A.; Kumar, R.; Barfidokht, A.; Kim, J.; Musameh, M.M.; Kyratzis, I.L.; Wang, J. Wearable Flexible and Stretchable Glove Biosensor for On-Site Detection of Organophosphorus Chemical Threats. ACS Sens. 2017, 2, 553-561. [CrossRef] [PubMed] 
118. Mishra, R.K.; Barfidokht, A.; Karajic, A.; Sempionatto, J.R.; Wang, J.; Wang, J. Wearable potentiometric tattoo biosensor for on-body detection of G-type nerve agents simulants. Sens. Actuators B Chem. 2018, 273, 966-972. [CrossRef]

119. Kim, J.; Jeerapan, I.; Sempionatto, J.R.; Barfidokht, A.; Mishra, R.K.; Campbell, A.S.; Hubble, L.J.; Wang, J. Wearable Bioelectronics: Enzyme-Based Body-Worn Electronic Devices. Acc. Chem. Res. 2018, 51, 2820-2828. [CrossRef] [PubMed]

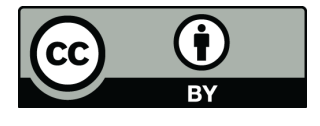

(C) 2018 by the authors. Licensee MDPI, Basel, Switzerland. This article is an open access article distributed under the terms and conditions of the Creative Commons Attribution (CC BY) license (http://creativecommons.org/licenses/by/4.0/). 